\title{
Time to adapt exercise training regimens in pulmonary rehabilitation - a review of the literature
}

This article was published in the following Dove Press journal: International Journal of COPD

10 November 2014

Number of times this article has been viewed

\author{
Annemarie L Lee ${ }^{1-4}$ \\ Anne E Holland ${ }^{1-3}$ \\ 'Physiotherapy, Alfred Health, \\ Melbourne, VIC, Australia; ${ }^{2}$ Institute \\ for Breathing and Sleep, Austin \\ Health, Melbourne, VIC, Australia; \\ ${ }^{3}$ Physiotherapy, La Trobe University, \\ Melbourne, VIC, Australia; ${ }^{4}$ Westpark \\ Healthcare Centre, ON, Canada
}

\begin{abstract}
Exercise intolerance, exertional dyspnea, reduced health-related quality of life, and acute exacerbations are features characteristic of chronic obstructive pulmonary disease (COPD). Patients with a primary diagnosis of COPD often report comorbidities and other secondary manifestations, which diversifies the clinical presentation. Pulmonary rehabilitation that includes whole body exercise training is a critical part of management, and core programs involve endurance and resistance training for the upper and lower limbs. Improvement in maximal and submaximal exercise capacity, dyspnea, fatigue, health-related quality of life, and psychological symptoms are outcomes associated with exercise training in pulmonary rehabilitation, irrespective of the clinical state in which it is commenced. There may be benefits for the health care system as well as the individual patient, with fewer exacerbations and subsequent hospitalization reported with exercise training. The varying clinical profile of COPD may direct the need for modification to traditional training strategies for some patients. Interval training, one-legged cycling (partitioning) and non-linear periodized training appear to be equally or more effective than continuous training. Inspiratory muscle training may have a role as an adjunct to whole body training in selected patients. The benefits of balance training are also emerging. Strategies to ensure that health enhancing behaviors are adopted and maintained are essential. These may include training for an extended duration, alternative environments to undertake the initial program, maintenance programs following initial exercise training, program repetition, and incorporation of approaches to address behavioral change. This may be complemented by methods designed to maximize uptake and completion of a pulmonary rehabilitation program.
\end{abstract}

Keywords: pulmonary rehabilitation, exercise training, chronic obstructive pulmonary disease

\section{Introduction to pulmonary rehabilitation and its impact on COPD}

Chronic obstructive pulmonary disease (COPD) is an irreversible condition, characterized by airflow limitation and chronic inflammation of the airways. ${ }^{1}$ The clinical profile includes dyspnea, fatigue, reduced exercise tolerance, and diminished physical activity (PA), contributing to a poorer health-related quality of life (HRQOL). ${ }^{1}$ Physiological impairments include respiratory and skeletal muscle dysfunction, ${ }^{2}$ together with sleep disruption ${ }^{3}$ and symptoms of anxiety and depression ${ }^{4,5}$ are often observed. The heterogeneous nature of COPD is further illustrated by variable body composition abnormalities and nutritional deficits ${ }^{6}$ as well as other concurrent medical conditions including cardiovascular disease, diabetes, osteoporosis, and osteoarthritis. ${ }^{7,8}$
Correspondence: Annemarie L Lee Westpark Healthcare Centre, 82 Buttonwood Avenue, Toronto, M6M 2J5, ON, Canada

Tel +l 4l62433600 ext 2653

Email annemarie.lee@westpark.org 
Other complications may be greater deficits in balance and postural control. ${ }^{9}$ People with COPD frequently experience acute exacerbations (AE), with increased dyspnea, worsening fatigue, decline in lung function, ${ }^{10}$ and acute reductions in PA $^{11}$ commonly detected. Diminished PA is linked to an increased risk of readmission and mortality, ${ }^{12}$ and has been identified as the strongest predictor of survival in stable COPD. ${ }^{13} \mathrm{AE}$ and subsequent hospitalization are the leading causes of significant morbidity and mortality. ${ }^{1}$

Pulmonary rehabilitation (PR) is a cornerstone of management of COPD. It is defined as a "comprehensive intervention based on a thorough patient assessment followed by patient-tailored therapies that include, but are not limited to, exercise training, education and behaviour change, designed to improve the physical and psychological condition of people with chronic respiratory disease and to promote the long-term adherence to health-enhancing behaviours". ${ }^{6}$ The aim of exercise prescription in PR is to address the multiple contributors to exercise limitation, including ventilatory and cardiovascular limitations, gas exchange abnormalities, and peripheral and respiratory muscle changes. These physiological changes manifest as reduced exercise capacity leading to impairment in functional status, ${ }^{14,15}$ as illustrated in Figure 1.

As an interdisciplinary intervention that aims to improve physical well-being while enhancing disease management, PR is advocated irrespective of the stage of lung disease. Functional improvements and physiological adaptations have been achieved in patients whose Global Initiative on Obstructive Lung Disease (GOLD) stage ranged from II to IV. ${ }^{16}$ Patients classified with mild COPD also gain significant clinical improvements. ${ }^{17}$ The broad beneficial effects of PR on patient-centered outcomes are accompanied by longterm outcomes such as reduced exacerbation frequency and decreased hospital admissions. ${ }^{18}$

The benefits and outcomes associated with PR are well accepted, with PR forming part of standard care for COPD. ${ }^{1}$ However, despite large and clinically meaningful improvements in clinical trials, it is recognized that there is some heterogeneity in response between individuals, with some people not achieving meaningful improvements. ${ }^{19}$ There are also challenges associated with low program uptake and adherence. With PR, a long-term treatment for this complex condition, there is a clear need to optimize approaches to

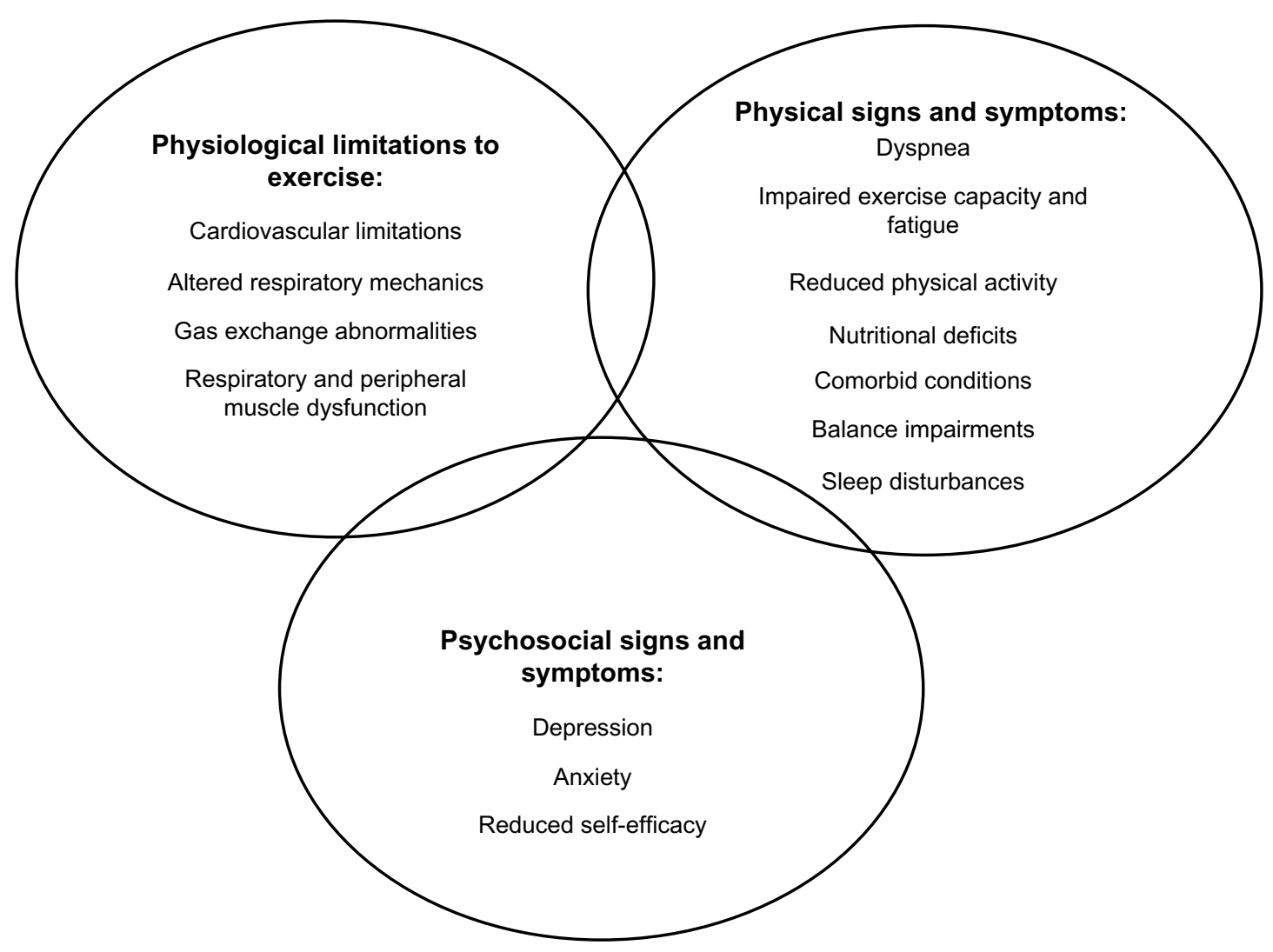

Figure I Multi-factorial nature of exercise limitation in chronic obstructive pulmonary disease. 
exercise training and models of PR to maximize the benefits for an individual's clinical presentation.

This review examines the evidence underlying the effectiveness of exercise training regimens and program models for PR for patients with COPD. The short and long-term benefits linked to conducting exercise programs and the possible strategies for improving overall HRQOL in this context are also outlined. Some limitations and challenges with optimizing training program uptake will be discussed.

\section{Review of evidence supporting the effectiveness of training regimens as part of $\mathbf{P R}$ Endurance training}

Exercise training in the form of endurance and resistance training is recognized as the optimal approach for improving muscle function in COPD. Key principles of endurance exercise prescription for COPD incorporate frequency, intensity, duration, type, and mode. ${ }^{20}$ To optimally prescribe endurance training, an exercise test is completed prior to training commencement. Cardiopulmonary exercise tests (treadmill or cycle), using an incremental or constant work rate protocol ${ }^{21}$ are undertaken to provide physiological measurements of exercise limitations and appropriate training load. Other options are field walking tests, including the 6-minute walk test (6MWT), incremental shuttle walk test or endurance shuttle walk test (ESWT). The peak work rate, peak exercise/walking capacity, peak oxygen uptake $\left(\mathrm{VO}_{2}\right.$ peak) or heart rate at the gas exchange threshold derived from these tests are used to set endurance exercise prescription. ${ }^{6,21}$

The recommended frequency for targeting skeletal muscle physiological adaptations and achieving benefits is a minimum of 3 times per week, with a mix of supervised and unsupervised sessions, for a duration of 8 weeks. ${ }^{21}$ High intensity training, defined as greater than $60 \%$ of maximal work rate for a duration of 20 to 60 minutes $^{22}$ is associated with greater benefits compared to lower intensity. The selection of this intensity is based on the rationale for addressing skeletal muscle weakness, with a sufficient anabolic stimulus required to target the skeletal muscle's oxidative capacity. ${ }^{23} \mathrm{In}$ patients with COPD, a target level for symptoms of dyspnea of 4 to 6 (moderate to very severe) or rating of perceived exertion of 12 to 14 (somewhat hard) is considered to reflect an appropriate training intensity. ${ }^{6,21}$

There have been multiple studies and meta-analyses of PR in COPD examining the effects of this exercise prescription. ${ }^{24}$
The most common modes of endurance training tested in COPD are walking (ground-based or treadmill walking) and stationary cycling. ${ }^{25,26}$ This type of exercise is associated with improvement in maximal exercise capacity following endurance training, reflected by increased $\mathrm{VO}_{2}$ peak and peak work rate $22,25,27,28$ and greater endurance capacity ${ }^{29}$ for treadmill-based tests ${ }^{29}$ and cycle ergometry. ${ }^{29,30}$ The improvement in aerobic metabolism of skeletal muscles ${ }^{22,31}$ reduces the ventilation requirements for a given workload, which is reflected by reduced dyspnea and greater tolerance of daily activities. $^{22}$

Endurance training positively influences other patientcentered outcomes, including functional exercise capacity and HRQOL. Improved distances in field walking tests, including the 6-minute walk distance (6MWD), ${ }^{30}$ beyond the minimal important difference of 25 to $35 \mathrm{~m}^{32,33}$ have been consistently demonstrated. Similarly, positive changes in the incremental shuttle walk test ${ }^{34}$ and ESWT ${ }^{35,36}$ are evident. Overall, the effect of initial outpatient PR programs on HRQOL is positive $\mathrm{e}^{1,24,37,38}$ and is frequently accompanied by a reduction in anxiety and depression. ${ }^{39}$ Similar results are achieved with PR initiated immediately post-AE. ${ }^{18}$ More recently, improvement has been noted in measures of health status according to the COPD assessment test. ${ }^{40,41}$

From a practical perspective, the mode of endurance training may be important. Ground-based walking (applied at an intensity of $75 \%$ peak walking capacity) is equally beneficial compared to cycling (intensity of $60 \%$ peak work capacity) in improving both peak walking and cycling capacity but achieves a greater ESWT time. ${ }^{35}$ This, together with the minimal equipment for ground-based walking supports the option for endurance training for a broader population of patients, ${ }^{42}$ particularly in the absence of other training modes.

\section{Interval training}

It is well recognized that not all individuals with COPD are able to perform high intensity training, due to intolerable dyspnea, peripheral fatigue or anxiety, ${ }^{43}$ which can influence the achievement of a physiological training effect over the course of a program. ${ }^{25}$ Interval training is used as an alternative mode that may be better tolerated. Interval training consists of periods of high-intensity exercise (20 seconds to 3 minutes) interspersed with either rest or lower intensity training (30 seconds to 3 minutes). This approach imposes a maximal load on peripheral muscles without engagement of anaerobic metabolism, ${ }^{43-45}$ enabling exercise to be undertaken with more favorable cardiorespiratory responses. ${ }^{45}$ 
This training mode is an alternative for patients with severe COPD, whose tolerance of high work rates is limited to less than 5 minutes. ${ }^{46}$ Interval training during cycling or walking avoids the need for prolonged rest periods, therefore minimizing the interruption of exercise flow, and is able to be completed with less dyspnea and leg fatigue ${ }^{43-46}$ whilst achieving muscle adaptations equivalent to continuous training. ${ }^{16}$ A systematic review found that interval and continuous training resulted in similar improvements for $\mathrm{VO}_{2}$ peak, 6MWD, and HRQOL following training completion. ${ }^{47}$ Achieving comparable benefits is dependent on the same amount of work being performed for both training modes, ${ }^{43,48}$ as total work is an important determinant of training response.

\section{Resistance training}

Resistance training is an essential component of PR, which focuses on the activation of local muscle groups in repetitive lifting exercises of relatively high load. ${ }^{2,49,50}$ Commonly targeted muscle groups and options for resistance training in PR are outlined in Table $1 .{ }^{51}$ Overall improvement in muscle strength is achieved with both upper and lower limb resistance training. ${ }^{49,52,53}$ even when resistance training was applied in conjunction with aerobic training, ${ }^{49}$ a common approach in most PR programs. This increased muscle strength is reflected by improved performance of functional activities $^{49,53}$ particularly when exercises closely replicate daily activities.

Table I Lower and upper limb muscle groups targeted for resistance training and options for exercise

\begin{tabular}{ll}
\hline Muscles targeted & Type of exercise \\
\hline Lower limb training & \\
Quadriceps & Free weights \\
Hamstrings & Weight machine \\
Gluteus maximum/medius & - Leg press, quadriceps extension \\
Gastrocnemius & Elastic bands \\
Soleus & Pulleys \\
& Functional tasks \\
& - Sit-stand, step-ups or stair climbing, \\
& squats, straight leg raise \\
Upper limb training & Supported \\
Pectoralis major/minor & - Arm ergometry \\
Latissimus dorsi & - Weight machine \\
Trapezius & - Chest press, latissimus pull-down \\
Triceps & Unsupported \\
Biceps & - Free weights \\
& - Elastic bands \\
& - Dowel lifts \\
& - Wall push offs \\
& - Functional tasks \\
& - Ball throwing against a wall \\
\hline
\end{tabular}

The impact of upper limb training on dyspnea levels during domestic activities and upon HRQOL is less encouraging, with no significant reduction in breathlessness in either supported or unsupported training. ${ }^{54}$ To positively influence dyspnea levels, a longer duration of training (greater than 8 weeks) may be necessary. ${ }^{53}$ This lack of impact on dyspnea may also be related to the dual role of upper limb musculature as an accessory to respiration. In COPD, when unsupported arms are raised above shoulder height, the ability of the upper limb muscles to support the shoulder girdle and participate in daily tasks is compromised by the need to support respiration. ${ }^{55}$ To achieve a reduction in dyspnea with upper limb training, the specific breathing pattern during these tasks may be significant. A recent study of patients with severe COPD and hyperinflation undertook a constant load arm lifting task to symptom intolerance and were randomly assigned to either inhale during the lift, exhale during the lift or unconstrained breathing. ${ }^{56}$ The breathing strategy of exhaling during the lift was associated with significantly greater endurance of the task. ${ }^{56}$ This approach could be easily adopted for upper limb resistance training to maximize performance, which may translate into reduced symptoms over a longer training duration.

When resistance training (incorporating upper and lower limb exercises) is compared to endurance training alone or a combination of both, the improvement in maximal working capacity during an incremental cycle test and HRQOL was similar between all forms of exercise. ${ }^{57}$ The lower oxygen consumption and dyspnea scores ${ }^{56}$ provoked during resistance training suggest that for patients who are limited in their ability to undertake endurance training in either a continuous or interval mode, resistance training may be as effective, but better tolerated. ${ }^{58}$

The prescription for resistance training is based on the principles of one-repetition maximum. This is defined as the maximum load which can be moved once only over the full range of motion without compensatory movements. ${ }^{50}$ For patients with COPD, the recommended prescription is 1 to 3 sets of 8 to 12 repetitions on 2 or 3 days per week, ${ }^{50}$ with loads ranging from $60 \%$ to $70 \%$ of the one repetition maximum or a load that provokes fatigue following 8 to 12 repetitions. $^{2}$ The principle of overload is critical, with increase in loads over time required to maximize training gains.

A number of resistance training studies have used expensive gym-based equipment, which may not be accessible in all PR settings. An alternative is the use of elastic tubing, which has been recently compared to traditional 
resistance equipment. A greater improvement in the 6MWD (73 $\mathrm{m}$ versus $42 \mathrm{~m}, P<0.05$ ) was achieved with elastic tube training, although both types were equally effective in improving muscle strength and HRQOL.$^{59}$ For this reason, elastic tubing may be a practical option when access to free weights or specialized resistance equipment is limited or unavailable. In addition, this mode may be more readily translated to a home exercise program.

\section{Advanced exercise prescription models}

Traditional approaches to exercise training in COPD have used simple exercise prescription, with gradual increases in load over time. More sophisticated approaches which have been applied in healthy sedentary and trained individuals may give rise to better outcomes. ${ }^{60}$ One of these approaches is periodization. Periodization or variation in training involves the manipulation of training variables to maximize adaptations, minimize overtraining, and attain a training effect. ${ }^{60}$ Non-linear periodized exercise training is characterized by training intensity, duration, and repetition-volume which are altered frequently and interspersed with adequate recovery for optimizing performance during endurance and resistance training. ${ }^{60}$ This approach has been recently investigated in patients with severe COPD. ${ }^{61}$ Over a 10 week course, patients trained with traditional endurance and resistance training or non-linear periodized training (with a variation of aerobic cycle training combined with high-volume, low intensity resistance training and anaerobic cycling with low-volume, moderate to high intensity resistance training). Greater statistical and clinically significant improvement in cycle endurance (by 300 seconds) and all domains of HRQOL, including dyspnea and fatigue was achieved with non-linear periodized training compared to traditional prescription. ${ }^{61}$ While this method requires more exploration in COPD, these preliminary results suggest it may have positive outcomes. Specialist equipment is not required, but the exercise prescription is more complex than current models and clinicians would require specific training in establishing individual exercise recommendations and modes of progression for effective delivery.

\section{One-legged training or partitioning}

An alternative method to enhance the beneficial effects from endurance training whilst minimizing the ventilatory load can be achieved via partitioning exercise to a smaller muscle group, while maintaining the same muscle load. Onelegged cycling has been explored as a mode of partitioning. During a constant power exercise test, compared to twolegged cycling (intensity of $70 \%$ peak power), one-legged cycling (intensity of 35\% two-legged peak power) induced an equivalent metabolic demand, at a lower minute ventilation and less dyspnea. ${ }^{62}$ This novel approach may enhance the effectiveness of endurance training in COPD, with patients able to increase their work capacity. When applied for 7 weeks, three times weekly, a greater increase in $\mathrm{VO}_{2}$ peak was achieved with one-legged cycling group (15 minutes per leg) versus the two-legged cycling (30 minutes in total) group. ${ }^{63}$ Practically, this approach may require patients to initially perform an incremental cycle ergometer test to set the target intensity. Intensity is then progressed once the duration (30 minutes total) was achieved. The training requires a suitable (fixed wheel/non-free wheeling or counterweight on the inactive pedal) cycle ergometer, with patients resting their inactive foot on the crossbar located midway on the head of the ergometer cycle during the one-legged mode. While considered by patients to be comfortable and accepted without need for any position adjustment, the availability of these types of cycle ergometers within PR programs may influence the selection of patients for whom this mode of training is available.

\section{Inspiratory muscle training}

Respiratory muscle weakness has been observed in COPD, and is related to increased dyspnea, gas exchange abnormalities, and reduced exercise tolerance. ${ }^{64}$ This has led to interest in strategies to improve the respiratory muscle strength or endurance. Inspiratory muscle training (IMT) using a threshold or resistive load is the most common approach, with the prescription generally based on the maximal inspiratory pressure (PImax) is commonly used to improve inspiratory muscle strength. ${ }^{65}$ To measure PImax, a patient breathes through a mouthpiece, with a firm lip seal to prevent glottis closure during a maximum inspiratory maneuver. The patient exhales slowly to residual volume, then inhales maximally, maintaining an inspiratory pressure for at least 1.5 seconds, so that the maximum pressure can be recorded. This maneuver is repeated five times, with encouragement, with 1 minute rest between each measurement. ${ }^{66}$ While the optimal training intensity is not known, and has ranged from $15 \%$ to $80 \%$ of PImax, an initial resistance greater than $30 \%$ of PImax is recommended and is increased in a stepwise manner. ${ }^{66}$ While the optimal duration is uncertain, the majority of studies provided a total exercise time of 30 to 60 minutes per day, with sessions often split into 2 or 3 sessions, ${ }^{66}$ for an average of 3 to 7 days per week. IMT significantly improved inspiratory muscle strength and endurance and 
reduced dyspnea. ${ }^{66,67}$ However, when added to a standard whole-body exercise program in PR, no additional benefit for HRQOL or exercise capacity was observed. For patients with significant respiratory muscle weakness, defined as a PImax less than $60 \mathrm{cmH}_{2} \mathrm{O}$, it is possible that IMT is an optimal addition to exercise training, particularly if the respiratory muscle deficits are significantly impacting on endurance or resistance training. This however, would require careful assessment of respiratory muscle function prior to implementation.

\section{Balance training}

Balance training is emerging as an adjunct to traditional PR training regimens. Balance deficits and postural control alterations are linked to an increased risk of falling and fear of falling in COPD. ${ }^{9,68}$ In a preliminary study of balance training for 6 weeks during inpatient rehabilitation in patients with severe COPD, the intervention group received circuit training including stance exercises, gait, transition, and functional strengthening, in addition to routine endurance and strength training, while the comparison group received traditional PR. ${ }^{69}$ Improvement in the clinical measures of balance of the Berg Balance Scale, Balance Evaluation Systems Test, and self-reported physical function was seen only following balance-specific training. ${ }^{69,70}$ While this is a preliminary study conducted among inpatients, the positive outcomes lend support to the possible role of balance training for those with COPD who are at risk of falls.

\section{Strategies to optimize and maintain outcomes for people with COPD}

Following completion of an initial PR program, improvement in exercise capacity and HRQOL are evident, ${ }^{24}$ however it has been reported that these improvements may diminish over time. Sustaining these gains is fundamental to ensuring long-term well-being in people with COPD. Although the ideal approach to achieve this has not been identified, there are a number of possible strategies which may be applied.

\section{Adjuncts to exercise training}

\section{Supplemental oxygen therapy}

\section{during exercise training}

For patients already prescribed long-term oxygen therapy at the commencement of PR, this should be continued during exercise training, with titration of flow rates to maintain adequate oxygenation. When applied specifically for the purposes of exercise training in PR, study findings are inconsistent, with reports of patients without exercise-induced desaturation achieving a higher training intensity and greater endurance capacity, ${ }^{71}$ while those with exercise-induced desaturation not exhibiting any improvement in exercise capacity or health status. ${ }^{72,73}$ For this reason, an unequivocal recommendation for use of supplemental oxygen therapy for patients with COPD during exercise training is currently not warranted. Assessment of desaturation during exercise tolerance testing on room air at baseline, along with individual response to supplemental oxygen, provides guidance as to which individual patients may benefit from oxygen supplementation during exercise training.

\section{Non-invasive ventilation}

In patients with COPD, expiratory flow limitation and dynamic hyperinflation during exercise training may increase the work of breathing and has been associated with early termination of exercise at a lower workload. ${ }^{74}$ To unload the respiratory muscles and reduce the work of breathing, non-invasive positive pressure ventilation (NIV) has been applied as an adjunct to training. ${ }^{75}$ A systematic review of patients with severe to very severe COPD found that NIV improved peak exercise (17\% improvement) and endurance exercise capacity (59\% improvement), which was accompanied by an increase in training intensity by $13 \%$ compared to sham NIV, although the effects on functional exercise capacity and HRQOL were less clearly defined. ${ }^{76}$ The application of NIV requires not only additional equipment, but experience in the initial setup, titration of optimal pressures and assisting individual patients to adapt to the intervention during exercise training. For these reasons, its practical use may be reserved for patients who are significantly limited in their ability to achieve a sufficient training intensity during endurance or resistance training due to marked dynamic hyperinflation and intolerable dyspnea.

\section{Program duration}

While the optimal length has not been identified, a systematic review suggested that programs of a longer duration (up to 12-18 months) are associated with more favorable outcomes on HRQOL, although the impact on exercise capacity is less clear. ${ }^{77}$ While the current recommendation for a PR program is 8 weeks, the possibility of extending this duration for patients who may require a longer length of time to achieve clinical improvements may be an important consideration.

\section{Program setting}

The limited uptake rate of patients attending PR is well described, with less than $5 \%$ of patients per year accessing PR. ${ }^{78}$ 
Practical reasons are program shortage, insufficient health professionals, and patient-related factors, of which the most common reasons are difficulties with transportation and travel. ${ }^{79-81}$ Institution-based programs may not be universally appealing and alternative models for PR may be more suitable. Home-based programs have been found to be a safe option, with equivalent improvements in HRQOL and exercise capacity in comparisons of hospital versus home-based groups. ${ }^{82}$ However, to date home-based PR has not been widely adopted into clinical practice, possibly because a sound economic model has not been developed. Further work is required to determine whether home-based PR can deliver good patientcentered outcomes in a cost-effective manner.

\section{Maintenance programs}

The ability to maintain improvements in HRQOL and exercise capacity beyond the immediate intervention period may be facilitated by supervised maintenance exercise programs, which could assist in ensuring continuity of training. Maintenance programs may take various forms, including hospital-based and community settings, with frequencies ranging from 3 times per week to once monthly and different training intensities. Aerobic exercise (walking or cycling) is always included, with most including lower and/or upper extremity resistance training. ${ }^{83} \mathrm{~A}$ metaanalysis found significant improvement in exercise capacity after undertaking 6 months of training, but this was not sustained at 12 months, and a positive impact on HRQOL was not achieved. ${ }^{83}$ Despite only medium-term benefits, the ongoing contact with health professionals and the encouragement of a home program may assist in optimizing exercise intensity to maintain a sufficient training stimulus for individual patients. The programs may also provide the opportunity to continually reinforce healthy behavioral messages introduced during an initial program.

Attrition rates remain an issue in maintenance programs $^{83}$ and like the setting of an initial PR program, program location may be important. While the majority of programs are undertaken within the hospital setting, a recent study of community-based maintenance has been explored. ${ }^{84} \mathrm{~A}$ twice weekly program for 1 year supervised by fitness consultants at a local community center was found to be a feasible model which preserved the benefits in exercise capacity and HRQOL achieved during an initial, institution-based PR program. This lends support for the more extensive role of maintenance programs within the community, which may be more geographically appealing to patients.

\section{Self-efficacy}

A critical factor in sustaining improvements over both the short- and long-term is an individual patient's approach towards exercise and the need for ongoing health mentoring. Self-efficacy explores both the coping skills of an individual and their emotional function and is believed to be a predictor of health behavior. ${ }^{85,86}$ It reflects a person's belief in their ability to control, organize, undertake, and complete a goal-orientated activity. PR has been reported to improve self-efficacy ${ }^{87}$ being the ideal environment to target coping skills ${ }^{88}$ and to introduce and promote strategies to optimize health behavior. The social support from peers is important to patients and may enhance motivation. ${ }^{89}$ This motivation may be a critical factor in maintaining a physically active lifestyle after PR. With some patients requiring more extensive and frequent support, the ongoing peer support during maintenance and follow-up programs may be pertinent to sustaining self-efficacy over the longer duration.

\section{Repeating PR}

In view of the decline in benefits over the longer term, another strategy is PR repetition. There have been 5 studies which have explored the effects of program repetition in COPD,${ }^{90-94}$ with their findings outlined in Table 2. Overall results demonstrated that while program repetition was associated with significant gains in exercise tolerance and HRQOL, the magnitude of improvement did not consistently reach a clinically important threshold. A retrospective study demonstrated that in a clinical program, 20\% of patients repeat PR over a period of 9 years. ${ }^{94}$ Patients with a smaller change in mastery following their initial PR program were more likely to repeat, suggesting that if self-efficacy is not effectively addressed in the initial program, the need for PR repetition is likely to be higher. Although the optimal timing around program repetition is unclear, repeating PR may be suitable for patients who are at risk of decline and whose access to maintenance programs is limited. Further study of the role and timing of program repetition is required to answer these questions.

\section{Comorbidities}

Physical limitations impair the ability to engage in an active lifestyle. ${ }^{89}$ This was highlighted in a recent study where people with COPD and comorbidities (including obesity, musculoskeletal or neurological conditions) engaged in only 25 minutes of moderate intensity PA compared to 104 minutes in those without comorbidities. ${ }^{95}$ Comorbidities in COPD may have a negative influence on PR outcomes ${ }^{96}$ 


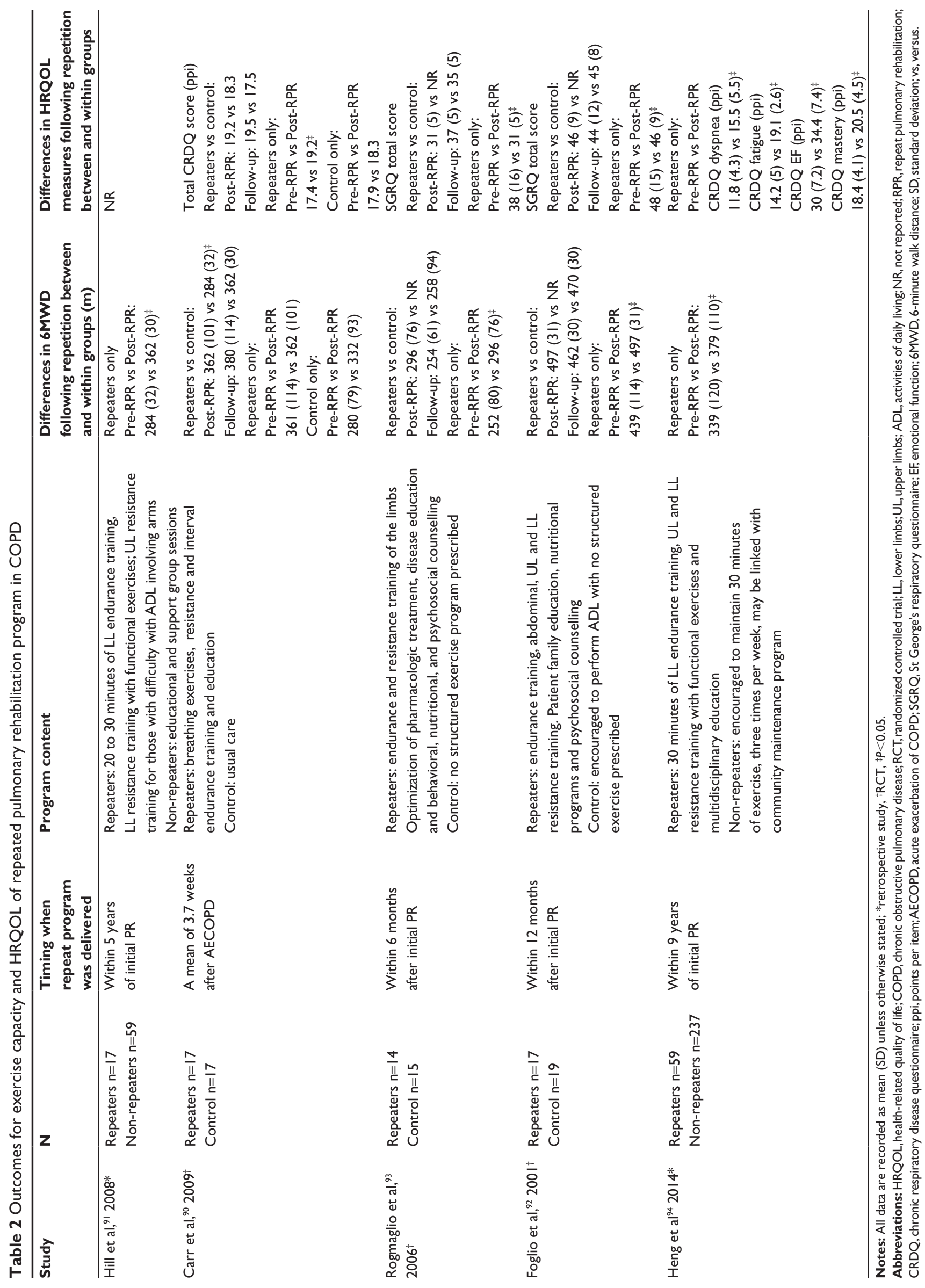


due to physical restrictions and pain experienced during traditional training programs. One alternative approach may be water-based training. High intensity water-based training was associated with clinically significant improvements in HRQOL activity measures and exercise capacity (179 m versus $25 \mathrm{~m}$ ) compared to land-based activity in COPD. ${ }^{97}$ This approach may be even more effective for patients with comorbid conditions, with clinically significant improvements in the ESWT and fatigue levels with water-based training compared to land-based activities or control. ${ }^{98}$ Waterbased training should be considered as an alternative to traditional land-based programs in any patient in whom physical comorbidities limit the nature or intensity of training.

\section{Benefits of PR across the disease course}

The benefits of PR are evident when it is applied across the disease course, including, immediately post AE and in a stable clinical state. A summary of the different modes of exercise training and their levels of evidence in differing clinical states is outlined in Figure 2. Over the longer term, these benefits may translate into reduced health care costs. ${ }^{6,18}$

\section{PR immediately post $A E$}

The effect of exercise programs initiated early post AE (usually at hospital discharge) has been explored in a systematic review. ${ }^{18}$ The structure of PR ranged from inpatient only, inpatient followed by an outpatient program, institution-based outpatient or home-based program only. Time of commencement ranged from within 3 to 7 days of hospital admission or immediately following discharge (within 6 to 10 days). Program format was variable, with a mix of endurance exercise for 10 days, followed by 6 months of home-based

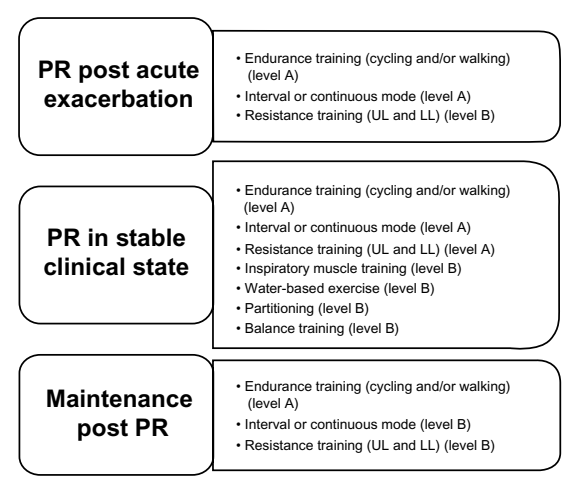

Figure 2 Summary of exercise training options for different clinical stages of COPD and levels of evidence.

Note: Levels of evidence are based on NHLBI/WHO Workshop Report.'

Abbreviations: PR, pulmonary rehabilitation; UL, upper limbs; LL, lower limbs; COPD, chronic obstructive pulmonary disease; NHLBI, National Heart, Lung, and Blood Institute; WHO, World Health Organization. exercise, or strength and endurance training together with patient education, for a duration ranging from 3 to 12 weeks. Despite differences between program content, timing of commencement in relation to $\mathrm{AE}$ diagnosis and duration, clinically significant improvements in both exercise capacity and HRQOL were evident, with no adverse events. ${ }^{18}$ More importantly, PR commencement at this time reduced the rate of hospital readmission by $42 \%$ and mortality by $16 \%$. With hospitalization being a significant predictor of mortality in COPD,${ }^{1}$ reducing the incidence of these events over the short and longer term may delay the rate of clinical decline.

\section{$P R$ during an $A E$ of $C O P D$}

The majority of patients with COPD are referred and enrolled in PR programs when in a stable clinical state. However, there has been growing interest in the role of PR during an AE. Early studies showed that initiation of a formalized exercise program during an $\mathrm{AE}$ which incorporated both endurance and resistance training was feasible and associated with few adverse events. ${ }^{99}$ Furthermore, quadriceps resistance training for 7 days applied at an initial load of $70 \%$ of one repetition maximum in patients experiencing a severe exacerbation was associated with an increase in quadriceps force, which was sustained at 1 month post discharge. ${ }^{100}$ In addition, an anabolic response to training was achieved with resistance training, with no increase in systemic inflammation. ${ }^{100}$ Although these are positive findings, the results of a recent study of early PR initiated within 48 hours of a hospital admission suggest there is a need for caution when applying this intervention within this very early clinical phase. ${ }^{101}$ Daily walking and resistance training commenced in hospital and continued unsupervised in the home environment with telephone support did not reduce the risk of readmission and a higher mortality rate at 12 months was noted with early PR compared to usual care. ${ }^{101}$ While this suggests that PR and self-management strategies introduced during an $\mathrm{AE}$ are not risk free, it perhaps illustrates the need to ensure that exercise regimens and health behavior approaches are well understood by patients when predominantly performed in the home environment. It questions when post AE PR should be delivered and future research needs to clarify the benefits and risks of PR during an AE and the optimal time for delivery in COPD.

\section{$\mathrm{PR}$ and PA}

One of the key goals of PR is to encourage greater PA on a regular basis and promote adherence to this behavior. ${ }^{102}$ It is well documented that individuals with COPD spend less time walking and standing compared to their healthy-aged 
matched counterparts. ${ }^{103}$ The effect of PR on PA levels is encouraging, with small but significant improvements. ${ }^{104}$ The ability of PR programs to achieve improvement in PA is dependent on several factors; at the center is the need to address patient behavioral change to encourage compliance and self-efficacy, which may require a longer interval of time. ${ }^{105}$ This is illustrated by a $20 \%$ increase in walking time achieved after 6 months of training compared to a $7 \%$ increase following 3 months. ${ }^{106}$ The type of training utilized during the original program may also be important, with translation of exercise behavior possibly easier with modes that are accessible in daily life, such as ground-based walking. ${ }^{35}$

\section{Economic impact of PR}

Patients with COPD are major consumers of health care resources, ${ }^{107}$ with current estimations of cost to the health system between $\$ 800$ to $\$ 900$ million per annum in Australia. ${ }^{108}$ A substantial proportion of the economic burden of COPD is associated with hospitalization secondary to AE, with costs of USD4.5 billion and exceeding $£ 800$ million per annum in the UK. ${ }^{109,110}$ With the growing need to allocate limited health resources effectively, the evidence that PR reduces the incidence of $\mathrm{AE}$ and frequency of hospitalization is encouraging. ${ }^{111}$ There has been some economic analysis of PR in COPD, with three studies exploring elements of economic benefits of outpatient programs compared to standard care. ${ }^{12-114}$ A cost-utility study in the UK found a 6 week outpatient program to be associated with an improvement in quality-adjusted life years compared to standard case. ${ }^{112}$ Studies from the UK and Brazil found that an 8 week program was associated with significant direct health care cost savings, with fewer inpatient bed days and less outpatient physician reviews. ${ }^{13,114}$ These changes may translate to benefits to the overall health care system.

\section{Recommendations for the implementation and uptake of PR}

Uptake and completion: one of the challenges of PR lies in the initial uptake and successful completion of a program. Failure to attend initial PR is attributed to inconvenient timing, disruption to usual routine, and influence of their primary health care provider. ${ }^{79,80}$ Suboptimal attendance is commonly related to transport, lack of perceived benefit ${ }^{79,80}$ as well as hospitalization and social isolation, ${ }^{15,116}$ with less favorable outcomes achieved in non-completers of PR. ${ }^{19}$

A positive approach from the referring health professional has a significant influence on an individual patient's attitude towards an initial assessment. ${ }^{117}$ For this reason, the role of those referring patients to PR is critical, with the need for quality patient education to facilitate informed decision-making regarding attendance. The provision of summaries of information may be one option to facilitate this process. ${ }^{118}$ Identifying potential issues regarding attendance prior to commencement was explored through a study of group opt-in sessions prior to commencing PR. ${ }^{119}$ Discussion related to negative thinking, inactivity, and possible approaches to reverse or manage common symptoms were highlighted, and possible barriers to attendance were identified by potential participants. ${ }^{119}$ This provided the opportunity to consider solutions prior to program commencement, and was associated with improved graduation rates. ${ }^{119}$ Increased patient knowledge and individual comfort within a group environment may be important factors to optimize uptake and successfully implement an exercise program.

Facilitation of health behavioral change: the complexity of health behavioral change process ideally should be facilitated by health care professionals. Guiding patients requires an approach which includes tailored advice, encouraging elements of self-management where appropriate, increasing self-confidence, and facilitating the commencement of a home exercise program with the view to maintain training and PA beyond the program. ${ }^{119}$ Provision of both peer and professional exercise-focused support is recognized by patients to be important for maintaining an active lifestyle post PR and for optimal attendance rates during the program. ${ }^{79,120}$

Flexibility in program delivery: finally, some flexibility around exercise program provision may be necessary to ensure successful implementation. A common circumstance is the development of an AE during a training program. Continuation or recommencement of the program when interrupted is a suitable method to achieve clinically important outcomes.

\section{Conclusion}

COPD is a heterogeneous condition, with patients demonstrating physical, psychological, and functional disability in addition to comorbidities and complications which increase the complexity of clinical presentation. While the physical and psychosocial benefits of exercise training are well established, adaptation of programs to accommodate the varying clinical course of the disease and other manifestations of the condition are necessary. PR ideally should be offered in a stable clinical state and immediately following AE, although its role during $\mathrm{AE}$ requires further evaluation. In addition, the duration, frequency, and intensity of training should align with the recommended guidelines, ${ }^{6}$ but the 
way this is achieved may require modification of traditional training paradigms, to accommodate the needs of individual patients. Training strategies should consider the potential role of comorbidities or multi-morbidities in exercise training prescription and outcomes, and this area requires further research. Furthermore, the optimal approach to facilitate behavioral change is a continual challenge and further work is necessary to devise effective strategies in the short- and long-term to enhance attitudes towards exercise.

\section{Disclosure}

ALL and AEH have no disclosures or conflicts of interest in this work.

\section{References}

1. Global Initiative for Chronic Obstructive Lung Disease [homepage on the Internet]. Global strategy for diagnosis, management and prevention of chronic obstructive pulmonary disease; 2014. Available from: http:// www.goldcopd. Accessed March 29, 2014.

2. Maltais F, Decramer M, Casaburi R, et al. An official American Thoracic Society/European Respiratory Society Statement: Update on limb muscle dysfunction in chronic obstructive pulmonary disease. Am J Respir Crit Care Med. 2013;189(9):1121-1127.

3. Nunes DM, Mota RM, de Pontes Neto OL, Pereira ED, de Bruin VM, de Bruin PF. Impaired sleep reduces quality of life in chronic obstructive pulmonary disease. Lung. 2009;187(3):159-163.

4. Coventry PA. Does pulmonary rehabilitation reduce anxiety and depression in chronic obstructive pulmonary disease? Curr Opin Pulm Med. 2009;15(2):143-149.

5. Godoy RF, Teixeira PJ, Becker Junior B, Michelli M, Godoy DV. Late repercussions of a pulmonary rehabilitation program on the levels of anxiety, depression, quality of life and physical performance in patients with COPD. J Bras Pneumol. 2009;35(2):129-136.

6. Spruit MA, Singh SJ, Garvey C, et al. An official American Thoracic Society/European Respiratory Society Statement: Key concepts and advances in pulmonary rehabilitation. Am J Respir Crit Care Med. 2013;188(8):e13-e64.

7. Cazzola M, Bettoncelli G, Sessa E, Cricelli C, Biscione G. Prevalence of comorbidities in patients with chronic obstructive pulmonary disease. Respiration. 2010;80(2):112-119.

8. Crisafulli E, Costi S, Luppi F, et al. Role of comorbidities in a cohort of patients with COPD undergoing pulmonary rehabilitation. Thorax. 2008;63(6):487-492.

9. Smith MD, Chang AT, Seale HE, Walsh JR, Hodges PW. Balance is impaired in people with chronic obstructive pulmonary disease. Gait Posture. 2010;31(4):456-460.

10. Seemungal TA, Donaldson GC, Bhowmik A, Jeffries DJ, Wedzicha JA. Time course and recovery of exacerbations in patients with chronic obstructive pulmonary disease. Am J Respir Crit Care Med. 2000; 161(5):1608-1613.

11. Pitta F, Troosters T, Probst VS, Spruit MA, Decramer M, Gosselink R. Physical activity and hospitalisation for exacerbation of COPD. Chest. 2006;129(3):536-544.

12. Gimeno-Santos E, Frei A, Steurer-Stey C, et al. Determinants and outcomes of physical activity in patients with COPD: a systematic review. Thorax. 2014;69(8):731-739.

13. Waschki B, Kirsten A, Holz O, et al. Physical activity is the strongest predictor of all-cause mortality in patients with COPD: a prospective cohort study. Chest. 2011;140(2):331-343.

14. Annegarn J, Meijer K, Passos VL, et al. Problematic activities of daily living are weakly associated with clinical characteristics in COPD. J Am Med Dir Assoc. 2012;13(3):284-290.
15. Meijer K, Annegarn J, Lima Passos V, et al. Characteristics of daily arm activities in patients with COPD. Eur Respir J. 2014;43(6):1631-1641.

16. Vogiatzis I, Terzis G, Stratakos G, et al. Effect of pulmonary rehabilitation on peripheral muscle fiber remodeling in patients with COPD in GOLD stages II to IV. Chest. 2011;140(3):744-752.

17. Jácome $C$, Marques A. Impact of pulmonary rehabilitation in patients with mild COPD. Respir Care. 2014;59(10):1577-1582.

18. Puhan MA, Gimeno-Santos E, Scharplatz M, Troosters T, Walters EH, Steurer J. Pulmonary rehabilitation following exacerbations of chronic obstructive pulmonary disease. Cochrane Database Syst Rev. 2011;10:CD005305.

19. Troosters T, Gosselink R, Decramer M. Exercise training in COPD: how to distinguish responders from nonresponders. J Cardiopulm Rehabil. 2001;21(1):10-17.

20. Garber CE, Blissmer B, Deschenes MR, et al. American College of Sports Medicine position stand: quantity and quality of exercise for developing and maintaining cardiorespiratory, musculoskeletal and neuromotor fitness in apparently healthy adults: guidance for prescribing exercise. Med Sci Sports Exerc. 2011;43(7):1334-1359.

21. Nici L, Donner C, Wouters E, et al. American Thoracic Society/European Respiratory Society Statement on pulmonary rehabilitation. Am J Respir Crit Care Med. 2006;173(12):1390-1413.

22. Casaburi R, Patessio A, Ioli F, Zanaboni S, Donner CF, Wasserman K. Reductions in exercise lactic acidosis and ventilation as a result of exercise training in patients with obstructive lung disease. Am Rev Respir Dis. 1991;143(1):9-18.

23. Vogiatzis I, Stratakos G, Simoes DC, et al. Effects of rehabilitative exercise on peripheral muscle TNFalpha, Il-6, IGF-1 and MyoD expression in patients with COPD. Thorax. 2007;62(11): 950-956.

24. Lacasse Y, Goldstein R, Lasserson TJ, Martin S. Pulmonary rehabilitation for chronic obstructive pulmonary disease. Cochrane Database Syst Rev. 2006;4:CD003793.

25. Maltais F, LeBlanc P, Jobin J, et al. Intensity of training and physiologic adaptation in patients with chronic obstructive pulmonary disease. Am J Respir Crit Care Med. 1997;155(2):555-561.

26. Casaburi R, Porszasz J, Burns M, Carithers ER, Chang RS, Cooper CB. Physiologic benefits of exercise training in rehabilitation of patients with severe chronic obstructive pulmonary disease. Am J Respir Crit Care Med. 1997;155(5):1541-1551.

27. Gosselink R, Troosters T, Decramer M. Exercise training in COPD patients: the basic questions. Eur Respir J. 1997;10(12): 2884-2891.

28. Maltais F, Simard AA, Simard C, Jobin J, Despagnes P, Leblanc P. Oxidative capacity of the skeletal muscle and lactic acid kinetics during exercise in normal subjects and in patients with COPD. Am J Respir Crit Care Med. 1996;153:228-293.

29. Ries AL, Kaplan RM, Limberg TM, Prewitt LM. Effects of pulmonary rehabilitation on physiologic and psychosocial outcomes in patients with chronic obstructive pulmonary disease. Ann Intern Med. 1995;122(11):823-832.

30. Troosters T, Gosselink R, Decramer M. Short- and long term effects of outpatient rehabilitation in patients with chronic obstructive pulmonary disease: a randomized trial. Am J Med. 2000;109(3):207-212.

31. Maltais F, LeBlanc P, Simard C, et al. Skeletal muscle adaptation to endurance training in patients with chronic obstructive pulmonary disease. Am J Respir Crit Care Med. 1996;154(2 Pt 1):442-447.

32. Puhan MA, Mador MJ, Held U, Goldstein R, Guyatt GH, Schünemann HJ. Interpretation of treatment changes in 6-minute walk distance in patients with COPD. Eur Respir J. 2008;32(3):637-643.

33. Holland AE, Hill CJ, Rasekaba T, Lee A, Naughton MT, McDonald CF. Updating the minimal important difference for the 6-minute walk distance in patients with chronic obstructive pulmonary disease. Arch Phys Med Rehabil. 2010;91(2):221-225.

34. Singh SJ, Jones PW, Evans R, Morgan MD. Minimum clinically important improvement for the incremental shuttle walking test. Thorax. 2008;63(9):775-777. 
35. Leung RW, Alison JA, McKeough ZJ, Peters MJ. Ground walk training improves functional exercise capacity more than cycle training in people with chronic obstructive pulmonary disease (COPD): a randomised trial. J Physiother. 2010;56(2):105-112.

36. Revill SM, Morgan MD, Singh SJ, Williams J, Hardman AE. The endurance shuttle walk: a new field test for the assessment of endurance capacity in chronic obstructive pulmonary disease. Thorax. 1999;54(3):213-222.

37. Ries AL, Bauldoff GS, Carlin BW, et al. Pulmonary rehabilitation: joint ACCP/AACVPR evidence based clinical practice guidelines. Chest. 2007;131(Suppl 5):4S-42S.

38. Goldstein RS, Gort EH, Stubbing D, Avendano MA, Guyatt GH. Randomised controlled trial of respiratory rehabilitation. Lancet. 1994;344(8934):1394-1397.

39. Bratas O, Espnes GA, Rannestad T, Walstad R. Pulmonary rehabilitation reduces depression and enhances health-related quality of life in COPD patients - especially in patients with mild or moderate disease. Chron Respir Dis. 2010;7(4):229-237.

40. Jones PW, Harding G, Wiklund I, et al. Test of the responsiveness of the COPD Assessment Test following acute exacerbation and pulmonary rehabilitation. Chest. 2012;142(1):134-140.

41. Dodd JW, Hogg L, Nolan J, et al. The COPD Assessment Test (CAT): response to pulmonary rehabilitation. A multicentre, prospective study. Thorax. 2011;66(5):425-429.

42. Watts $\mathrm{S}, \mathrm{Ng} \mathrm{C}, \mathrm{McKeough} Z$, Jenkins S, et al. Effects of ground walking training in COPD: a randomised controlled trial. Eur Respir J 2014. In press 2014.

43. Vogiatzis I, Nasas S, Roussos C. Interval training as an alternative modality to continuous exercise in patients with COPD. Eur Respir J. 2002;20(1):12-19.

44. Sabapathy S, Kingsley RA, Schneider DA, Adams L, Morris NR. Continuous and intermittent exercise responses in individuals with chronic obstructive pulmonary disease. Thorax. 2004;59(12):1026-1031.

45. Vogiatzis I, Nanas S, Kastanakis E, Georgiadou O, Papazahou O, Roussos Ch. Dynamic hyperinflation and tolerance to interval exercise in patients with advanced COPD. Eur Respir J. 2004;24(3): 385-390.

46. Kortianou EA, Nasis IG, Spetsioti ST, Daskalakis AM, Vogiatzis I. Effectiveness of interval exercise training in patients with COPD. Cardiopulm Phys Ther J. 2010;21(3):12-19.

47. Beauchamp MK, Nonoyama M, Goldstein RS, et al. Interval versus continuous training in individuals with chronic obstructive pulmonary disease - a systematic review. Thorax. 2010;65(2):157-164.

48. Vogiatzis I, Terzis G, Nanas S, et al. Skeletal muscle adaptations to interval training in patients with advanced COPD. Chest. 2005;128(6):3838-3845.

49. O'Shea SD, Taylor NF, Paratz JD. Progressive resistance exercise improves muscle strength and may improve elements of performance of daily activities for people with COPD: a systematic review. Chest. 2009;136(5):1269-1283.

50. American College of Sports Medicine. American College of Sports Medicine position stand: progression models in resistance training for healthy adults. Med Sci Sports Exer. 2009;41(3):687-708.

51. Alison J, Barrack C, Cafarella P, et al. Pulmonary rehabilitation toolkit on behalf of The Australian Lung Foundation (2009). Available from: http://www.pulmonaryrehab.com.au. Accessed April 14, 2014.

52. Spruit M, Gosselink R, Troosters T, De Paepe K, Decramer M. Resistance versus endurance training in patients with COPD and peripheral muscle weakness. Eur Respir J. 2002;19(6):1072-1078.

53. Janaudis-Ferreira T, Hill K, Goldstein R, Wadell K, Brooks D. Arm exercise training in patients with chronic obstructive pulmonary disease: a systematic review. J Cardiopulm Rehabil Prev. 2009;29(5):277-283.

54. Janaudis-Ferreira T, Hill K, Goldstein RS, et al. Resistance arm training in patients with COPD: a randomised controlled trial. Chest. 2011;139(1):151-158.
55. Velloso M, Garcia Stella SG, Cendon S, Silva AC, Jardim JR. Metabolic and ventilatory parameters of four activities of daily living accomplished with arms in COPD patients. Chest. 2003;123(4):1047-1053.

56. Dolmage TE, Janaudis-Ferreira T, Hill K, Price S, Brooks D, Goldstein RS. Arm elevation and coordinated breathing strategies in patients with COPD. Chest. 2013;144(1):128-135.

57. Vonbank K, Strasser B, Mondrzyk J, et al. Strength training increases maximum working capacity in patients with COPD - randomised clinical trial comparing three training modalities. Respir Med. 2012;106(4):557-563.

58. Probst VS, Troosters T, Pitta F, Decramer M, Gosselink R. Cardiopulmonary stress during exercise training in patients with COPD. Eur Respir J. 2006;27(6):1110-1118.

59. Ramos EM, de Toledo-Arruda AC, Fosco LC, et al. The effects of elastic tubing-based resistance training compared with conventional resistance training in patients with moderate COPD: a randomised clinical trial. Clin Rehabil. Epub March 19, 2014.

60. Laursen PB. Training for intense exercise performance: high intensity of high volume training? Scand J Med Sci Sports. 2010;20 Suppl 2: $1-10$.

61. Klijn P, van Keimpema A, Legemaat M, Gosselink R, van Stel H. Nonlinear exercise training in advanced chronic obstructive pulmonary disease is superior to traditional exercise training: a randomized trial. Am J Respir Crit Care Med. 2013;188(2):193-200.

62. Dolmage TE, Goldstein RS. Response to one-legged cycling in patients with COPD. Chest. 2006;129(2):325-332.

63. Dolmage TE, Goldstein RS. Effects of one-legged exercise training of patients with COPD. Chest. 2008;133(2):370-376.

64. Decramer M, Demedts M, Rochette F, Billiet L. Maximal transrespiratory pressures in obstructive lung disease. Bull Eur Physiopathol Respir. 1980;16(4):479-490.

65. Gosselink, De Vos J, van den Houvel S, Segers J, Decramer M, Kwakkel G. Impact of inspiratory muscle training in patients with COPD: what is the evidence? Eur Respir J. 2011;37(2):416-425.

66. American Thoracic Society/European Respiratory Society. ATS/ERS Statement on Respiratory Muscle Testing. Am J Respir Crit Care Med. 2002;166(4):518-624.

67. O'Brien K, Geddes EL, Reid WD, Brooks D, Crowe J. Inspiratory muscle training compared to other rehabilitation interventions in chronic obstructive pulmonary disease: a systematic review update. J Cardiopulm Rehabil Prev. 2008;28(2):128-141

68. Beauchamp MK, Hill K, Goldstein RS, Janaudis-Ferreira T, Brooks D. Impairments in balance discriminate fallers from non-fallers in COPD. Respir Med. 2009;103(12):1885-1891.

69. Beauchamp MK, O’Hoski S, Goldstein RS, Brooks D. Effect of pulmonary rehabilitation on balance in persons with chronic obstructive pulmonary disease. Arch Phys Med Rehabil. 2010;91(9): 1460-1465.

70. Beauchamp MK, Janaudis-Ferreira T, Perreira V, et al. A randomized controlled trial of balance training during pulmonary rehabilitation for individuals with COPD. Chest. 2013;144(6):1803-1810.

71. Emtner M, Porszasz J, Burns M, Somfay A, Casaburi R. Benefits of supplemental oxygen in exercise training in nonhypoxemic chronic obstructive pulmonary disease patients. Am J Respir Crit Care Med. 2003;168(9):1034-1042.

72. Garrod R, Paul EA, Wedzicha JA. Supplemental oxygen during pulmonary rehabilitation in patients with COPD with exercise hypoxaemia. Thorax. 2000;55(7):539-543.

73. Nonoyama ML, Brooks D, Lacasse Y, Guyatt GH, Goldstein RS. Oxygen therapy during exercise training in chronic obstructive pulmonary disease. Cochrane Database Syst Rev. 2007;2:CD005372.

74. Marin JM, Carrizo SJ, Gascon M, Sanchez A, Gallego B, Celli BR. Inspiratory capacity, dynamic hyperinflation, breathlessness and exercise performance during the 6-minute walk test in chronic obstructive pulmonary disease. Am J Respir Crit Care Med. 2001;163(6): 1365-1399. 
75. Polkey MI, Kyroussis D, Mills GH, et al. Inspiratory pressure support reduces slowing of inspiratory muscle relaxation rate during exhaustive treadmill walking in severe COPD. Am J Respir Crit Care Med. 1996: 154(4 Pt 1):1146-1150.

76. Menadue C, Piper AJ, van’t Hul AJ, Wong KK. Non-invasive ventilation during exercise training for people with chronic obstructive pulmonary disease. Cochrane Database Syst Rev. 2014;5:CD007714.

77. Beauchamp MK, Janaudis-Ferreira T, Goldstein RS, Brooks D. Optimal duration of pulmonary rehabilitation for individuals with chronic obstructive pulmonary disease. Chron Respir Dis. 2011;8(2): 129-140.

78. Brooks D, Sottana R, Bell B, et al. Characterization of pulmonary rehabilitation programs in Canada in 2005. Can Respir J. 2007;14(2):87-92.

79. Arnold E, Bruton A, Ellis-Hill C. Adherence to pulmonary rehabilitation a qualitative study. Respir Med. 2006;100(10):1716-1723.

80. Keating A, Lee AL, Holland AE. Lack of perceived benefit and inadequate transport influence uptake and completion of pulmonary rehabilitation in people with chronic obstructive pulmonary disease: a qualitative study. J Physiother. 2011;57(3):183-190.

81. Fischer MJ, Scharloo M, Abbink JJ, et al. Participation and drop-out in pulmonary rehabilitation: a qualitative analysis of the patient's perspective. Clin Rehabil. 2007;21(3):212-221.

82. Maltais F, Bourbeau J, Shapiro S, et al. Effects of home-based pulmonary rehabilitation in patients with chronic obstructive pulmonary disease: a randomized trial. Ann Intern Med. 2008;149(12):869-878.

83. Beauchamp MK, Evans R, Janaudis-Ferreira T, Goldstein RS, Brooks D. Systematic review of supervised exercise programs after pulmonary rehabilitation in individuals with COPD. Chest. 2013;144(4):1124-1133.

84. Beauchamp MK, Francella S, Romano JM, Goldstein RS, Brooks D. A novel approach to long-term respiratory care: results of a communitybased post-rehabilitation maintenance program in COPD. Respir Med. 2013;107(8):1210-1216

85. Arnold R, Ranchor AV, Koeter GH, et al. Changes in personal control as a predictor of quality of life after pulmonary rehabilitation. Patient Educ Couns. 2006;61(1):99-108.

86. Bentsen SB, Wentzel-Larsen T, Henriksen AH, Rokne B, Wahl AK. Self-efficacy as a predictor of improvement in health status and overall quality of life in pulmonary rehabilitation - an exploratory study. Patient Educ Couns. 2010;81(1):5-13.

87. Vincent E, Sewell L, Wagg K, Deacon S, Williams J, Singh S. Measuring a change in self-efficacy following pulmonary rehabilitation an evaluation of the PRAISE tool. Chest. 2011;140(6):1534-1539.

88. Andenaes R, Bentsen SB, Hvinden K, Fagermoen MS, Lerdal A. The relationships of self-efficacy, physical activity and paid work to health-related quality of life among patients with chronic obstructive pulmonary disease (COPD). J Multidiscip Healthc. 2014;7: 239-247.

89. Stewart KF, Meis JJ, van de Bool C, Janssen DJ, Kremers SP, Schols AM. Maintenance of a physically active lifestyle after pulmonary rehabilitation in patients with COPD: a qualitative study towards motivational factors. J Am Med Dir Assoc. 2014;15(9):655-664.

90. Carr SJ, Hill K, Brooks D, Goldstein RS. Pulmonary rehabilitation after acute exacerbation of chronic obstructive pulmonary disease in patients who previously completed a pulmonary rehabilitation program. J Cardiopulm Rehabil Prev. 2009;29(5):318-324.

91. Hill K, Bansal V, Brooks D, Goldstein RS. Repeat pulmonary rehabilitation programs confer similar increases in functional exercise capacity in initial programs. J Cardiopulm Rehabil Prev. 2008;28(6):410-414.

92. Foglio K, Bianchi L, Bruletti G, Battista L, Pagani M, Ambrosino N. Long-term effectiveness of pulmonary rehabilitation in patients with chronic airway obstruction. Eur Respir J. 1999;13(1):125-132.

93. Romagnoli M, Dell'Orso D, Lorenzi C, et al. Repeated pulmonary rehabilitation in severe and disabled COPD patients. Respiration. 2006;73(6):769-776.
94. Heng H, Lee AL, Holland AE. Repeating pulmonary rehabilitation: prevalence, predictors and outcomes. Respirology. 2014;19(7): 999-1005.

95. McNamara RJ, McKeough ZJ, McKenzie DK, Alison JA. Physical comorbidities affect physical activity in COPD: a prospective cohort study. Respirology. 2014;19(6):866-872.

96. Hornikx M, Van Remoortel H, Demeyer H, et al. The influence of comorbidities on outcomes of pulmonary rehabilitation programs in patients with COPD: a systematic review. Biomed Res Int. 2013;146148.

97. Wadell K, Sudelin G, Henriksson-Larsen K, Lundgren R. High intensity physical group training in water - an effective training modality for patients with COPD. Respir Med. 2004;98(5):428-438.

98. McNamara RJ, McKeough ZJ, McKenzie DK, Alison JA. Water-based exercise in COPD with physical comorbidities: a randomised controlled trial. Eur Respir J. 2013;41(6):1284-1291.

99. Tang CY, Blackstock FC, Clarence M, Taylor NF. Early rehabilitation exercise program for inpatients during an acute exacerbation of chronic obstructive pulmonary disease. a randomised controlled trial. J Cardiopulm Rehabil Prev. 2012;32(3):163-169.

100. Troosters T, Probst VS, Crul T, et al. Resistance training prevents deterioration in quadriceps muscle function during acute exacerbations of chronic obstructive pulmonary disease. Am J Respir Crit Care Med. 2010;181(10):1072-1077.

101. Greening NJ, Williams JE, Hussain SF, et al. An early rehabilitation intervention to enhance recovery during hospital admission for an exacerbation of chronic respiratory disease: randomised controlled trial. BMJ. 2014;349:g4315.

102. Troosters T, Casaburi R, Gosselink R, Decramer M. Pulmonary rehabilitation in chronic obstructive pulmonary disease. Am J Respir Crit Care Med. 2005;172(1):19-38.

103. Pitta F, Troosters T, Spruit MA, Probst VS, Decramer M, Gosselink R. Characteristics of physical activities in daily life in chronic obstructive pulmonary disease. Am J Respir Crit Care Med. 2005;171(9):972-977.

104. Cindy Ng LW, Mackney J, Jenkins S, Hill K. Does exercise training change physical activity in people with COPD? A systematic review and meta-analysis. Chron Respir Dis. 2012;9(1):17-26.

105. Wempe JB, Wijkstra PJ. The influence of rehabilitation on behaviour modification in COPD. Patient Educ Couns. 2004;52(3):237-241.

106. Pitta F, Troosters T, Probst VS, Langer D, Decramer M, Gosselink R. Are patients with COPD more active after pulmonary rehabilitation? Chest. 2008;134(2):273-280.

107. Wouters EF. The burden of COPD in The Netherlands: results from the Confronting COPD survey. Respir Med. 2003;97 Suppl C:S51-S59.

108. National Heart, Lung, and Blood Institute [homepage on the Internet]. Australian Institute of Health and Welfare: Australia's Health 2010 Australia's health no 12. Cat no AUS 122. Canberra: AIHW; 2010. Available from: http://www.nhlbi.nih.gov/resources/docs/cht-book. htm. Accessed June 6, 2014

109. Guarascio AJ, Ray SM, Finch CK, Self TH. The clinical and economic burden of chronic obstructive pulmonary disease in the USA. Clinicoecon Outcomes Res. 2013;5:235-245.

110. National Institute for Health and Care Excellence [homepage on the Internet]. Chronic obstructive pulmonary disease: management of chronic obstructive pulmonary disease in adults in primary and secondary care; 2010. Available from: http://www.nice.org.uk/guidance/ CG101. Accessed August 2, 2014.

111. Rubi M, Renom F, Ramis F, et al. Effectiveness of pulmonary rehabilitation in reducing health resources use in chronic obstructive pulmonary disease. Arch Phys Med Rehabil. 2010;91(3):364-368.

112. Griffiths TL, Phillips CJ, Davies S, Burr ML, Campbell IA. Cost effectiveness of an outpatient multidisciplinary pulmonary rehabilitation programme. Thorax. 2000;56(10):779-784.

113. Chakravorty I, Fasakin C, Paine T, Narasimhaiah D, Austin G. Outpatient-based pulmonary rehabilitation for COPD: A cost of illness study. Pulmonology. 2011;364989. 
114. Farias CC, Resqueti V, Dias FA, Borghi-Silva A, Arena R, Fregonezi GA. Costs and benefits of pulmonary rehabilitation in chronic obstructive pulmonary disease: a randomised controlled trial. Braz J Phys Ther. 2014;18(2):165-173.

115. Young P, Dewse M, Fergusson W, Kolbe J. Respiratory rehabilitation in chronic obstructive pulmonary disease: predictors of nonadherence. Eur Respir J. 1999;13(4):855-859.

116. Garrod R, Marshall J, Barley E, Jones PW. Predictors of success and failure in pulmonary rehabilitation. Eur Respir J. 2006;27(4):788-794.

117. Bulley C, Donaghy M, Howden S, Salisbury L, Whiteford S, Mackay E. A prospective qualitative exploration of views about attending pulmonary rehabilitation. Physiother Res Inter. 2009;14(3):181-192.
118. Harris M, Smith BJ, Veale AJ, Esterman A, Frith PA, Selim P. Providing reviews of evidence to COPD patients: controlled prospective 12-month trial. Chron Respir Dis. 2009;6(3):165-173.

119. Graves J, Sandrey V, Graves T, Smith DL. Effectiveness of a group opt-in session on uptake and graduation rates for pulmonary rehabilitation. Chron Respir Dis. 2010;7(3):159-164.

120. Hogg L, Grant A, Garrod R, Fiddler H. People with COPD perceive ongoing, structured and socially supportive exercise opportunities to be important for maintaining an active lifestyle following pulmonary rehabilitation: a qualitative study. J Physiother. 2012;58(3): $189-195$.

\section{Publish your work in this journal}

The International Journal of COPD is an international, peer-reviewed journal of therapeutics and pharmacology focusing on concise rapid reporting of clinical studies and reviews in COPD. Special focus is given to the pathophysiological processes underlying the disease, intervention programs, patient focused education, and self management protocols.

\section{Dovepress}

This journal is indexed on PubMed Central, MedLine and CAS. The manuscript management system is completely online and includes a very quick and fair peer-review system, which is all easy to use. Visit $\mathrm{http} / / / \mathrm{www}$.dovepress.com/testimonials.php to read real quotes from published authors. 